\title{
Geometrical investigation of microchannel with two trapezoidal blocks subjected to laminar convective flows with and without boiling
}

\author{
Bruno Costa Feijó ${ }^{1}$, Ana Pavlovic ${ }^{2}$, Luiz Alberto Oliveira Rocha ${ }^{3}$, Liércio André Isoldi ${ }^{1}$, Sylvie \\ Lorente $^{4}$, Elizaldo Domingues dos Santos ${ }^{1}$ \\ ${ }^{1}$ School of Engineering, Universidade Federal do Rio Grande, Brazil, e-mail: bruno.feijo1989@gmail.com, \\ liercioisoldi@furg.br, elizaldosantos@furg.br \\ ${ }^{2}$ Department of Industrial Engineering, University of Bologna, Italy, e-mail: ana.pavlovic@ unibo.it \\ ${ }^{3}$ Department of Mechanical Engineering, Federal University of Rio Grande do Sul, Brazil, e-mail: \\ luizrocha@mecanica.ufrgs.br \\ ${ }^{4}$ Department of Mechanical Engineering, Villanova University, USA, e-mail: sylvie.lorente@ villanova.edu
}

\section{Article Info}

\section{Article history:}

Received October 12, 2021

Revised November 30, 2021

Accepted December 2, 2021

\section{Keywords:}

Heat transfer,

Boiling flow,

Microchannel,

Constructal Design,

Numerical study.

\begin{abstract}
Microchannels are important devices to improve the heat exchange in several engineering applications as heat, ventilation and air conditioning, microelectronic cooling, power generation systems and others. The present work performs a numerical study of a microchannel with two trapezoidal blocks subjected to laminar flows, aiming to analyze the influence of the boiling process on the geometric configuration of the microchannel. Constructal Design and Exhaustive Search are used for the geometrical evaluation of the blocks. The Mixture multi-phase model and the Lee phase change model were both employed for the numerical simulation of the boiling process. In this study, the influence of the height and higher width of the first block $\left(H_{11} / L_{11}\right)$ over the heat transfer rate and pressure drop for different magnitudes of the ratio between the lower width and higher width $\left(\mathrm{L}_{12} / \mathrm{L}_{11}\right)$ was investigated. It is considered water in monophase cases and water/vapor mixture for multiphase flow. Two different Reynolds numbers $\left(R e_{H}=0.1\right.$ and 10.0) were investigated. Results indicated that, for the present thermal conditions, the consideration of boiling flows were not significant for prediction of optimal configurations. Results also showed that in the cases where the boiling process was enabled, the multi-objective performance was higher than in the cases without boiling, especially for $\operatorname{Re}_{H}=0.1$.
\end{abstract}

Copyright (C) 2021 Regional Association for Security and crisis management and European centre for operational research. All rights reserved.

\section{Corresponding Author:}

Ana Pavlovic,

Department of Industrial Engineering, University of Bologna; email: ana.pavlovic@ unibo.it

\section{Introduction}

Microchannels usually have diameters between 0.01 and $0.2 \mathrm{~mm}$ (Kandlikar \& Grande, 2003) and differ significantly to conventional channels (those with a diameter larger than $3.0 \mathrm{~mm}$ ). They are employed in small and compact equipment like heat exchangers, microchips, nuclear reactors, bioengineering devices, among others, and have an important role in dissipating the heat that is generated by those systems. There are many studies in the last few decades about microchannels and they have focused mainly on understanding the physics of fluid flow and heat transfer and the aspects of microchannels that affect its performance such as the geometry, fluid and material properties, flow and heat parameters (Khan \& Fartay, 2011; Naqiuddin et al., 2018). 
The evolution of processing power in computers and the improvements of computational fluid dynamics (CFD) softwares have enabled the development and research of more complex problems, such as phase change, especially that of convective boiling flows. The boiling process happens in a microchannel when its walls are at a temperature higher than the saturation temperature, causing the formation of vapor bubbles on the liquid. This is a process that can lead to an increase in the heat transfer coefficient (Collier \& Thome, 1994; Rohsenow et al., 1998) and for that reason is a desired situation in many applications that have high rates of heat dissipation. Although, the boiling process still a considerably difficult problem compared to single phase flows because of the higher complexity of the physical phenomena involved (Kandlikar et al., 1999; Khan \& Fartaj, 2010). Most of the studies dedicated to numerically simulate boiling flows have focused on techniques for accurate reproduction of the boiling phenomenon (Setoodeh et al., 2020; Bathi et al., 2020; Naghibzadeh et al., 2020). Therefore, little research has been done so far with the aim of exploring the geometric aspects of microchannels subjected to boiling flows. There is strong evidence from single phase studies that the microchannels geometry can have a very important effect over the overall performance of the system (Ghani et al., 2017).

Regarding the geometry of the microchannel, the present work employs the Constructal Design method for its geometrical evaluation. This method is based on the Constructal Law of design and evolution (Bejan \& Lorente, 2008; Bejan \& Zane, 2012; Bejan \& Lorente, 2013; Bejan, 2020) which is a physical principle where the design patterns of flow systems, animate or inanimate, can be predicted deterministically by a physical principle of maximization of access of internal currents. Constructal Law states that "the design evolves in such a way as to facilitate access to the currents that flow into the finite size flow system" so these systems can continue to exist throughout of time. Constructal Law has encountered in engineering problems a good source of application of its principles, especially in the fields of fluid dynamics and heat transfer, where it has been proved very useful for the creation of efficient designs in flow systems. There is a wide number of works that have successfully applied the Constructal Design method in those areas in the last two decades (Rocha et al., 2002; Rocha et al., 2005; Biserni et al., 2007; Bello-Ochende et al., 2009; Lorenzini et al., 2012; Rodrigues et al., 2015; Gonzales et al., 2015; Hermany et al., 2018; Rodrigues et al., 2020; Magalhães et al., 2020; Moreira et al., 2021; Nunes et al., 2021). The Constructal Design method defines the search space, taking into account constraints and degrees of freedom, allowing the evaluation of the effect of system geometry variation over the performance indicators (which indicates the way to maximize the flow access to the system). It is important to not mistake the Constructal Design with a geometric optimization method. For this purpose, the Exhaustive Search was employed, which consists on the simulation of all the geometric possibilities of the search space, considering a step variation between the simulated geometries. An explanation about some methods of optimization associated with Constructal Design can be seen in the recent work of Gonzales et al. (2021).

This work performs a numerical study of convective boiling flows inside microchannels employing a CFD software, ANSYS FluentTM 14.5, based on the finite volume method (FVM). The Mixture multiphase model and the Lee phase change model were both employed to simulate the boiling process. The problem consists of a microchannel with $0.1 \mathrm{~mm}$ of height and $1.5 \mathrm{~mm}$ of length that has its walls with a constant temperature of $380 \mathrm{~K}$. The microchannel has two trapezoidal blocks mounted on its walls in an alternated form, being the first on the lower surface and the second on the upper surface, both with the same temperature imposed at the walls of the microchannel. A fluid, water in its liquid state, enters the microchannel and due to the temperature difference is forced to boil along the microchannel length. Constructal Design was applied to the geometry evaluation of the microchannel by means of four degrees of freedom and two constraints; while the Exhaustive Search was also applied for the geometrical optimization. Two different situations were analyzed and compared: with and without boiling. In addition, the geometric evaluation of both situations was done through a multi-objective approach, considering simultaneously the fluid dynamics and the thermal purposes. Therefore, the aim of this study is to analyze the influence of boiling on the effect of design over the pressure drop and heat transfer rate of the microchannel flow, as well as, to recommend geometric configurations for the problem. At the best of authors' knowledge, this kind of investigation was not previously performed in the literature, mainly by means of application of Constructal Design.

\section{Mathematical Modeling}

\subsection{Problem Description}

The present study consists on the problem of a two-dimensional microchannel with two trapezoidal blocks mounted on its walls (Figure 1) that is subjected to a convective boiling flow. The walls of microchannel, including the two blocks, are at a constant temperature of $T_{w}=380 \mathrm{~K}$, which is higher than the saturation point of the fluid $\left(T_{\text {sat }}=373.15 \mathrm{~K}\right)$, water. The fluid enters the microchannel with a temperature of $T_{\text {in }}=372 \mathrm{~K}$ and is considered incompressible. Due the temperature difference, the fluid is forced to boil along the microchannel

Geometrical investigation of microchannel with two trapezoidal blocks subjected... (Bruno Costa Feijó) 
and passes through the outlet as a mixture of liquid and vapor. The microchannel outlet is at atmospheric pressure $\left(P_{\text {out }}=0 \mathrm{~atm}\right)$. The microchannel has an operating pressure of $P=1 \mathrm{~atm}$ an its surfaces, the walls and blocks, are non-slip and impermeable $(u=v=0 \mathrm{~m} / \mathrm{s})$.

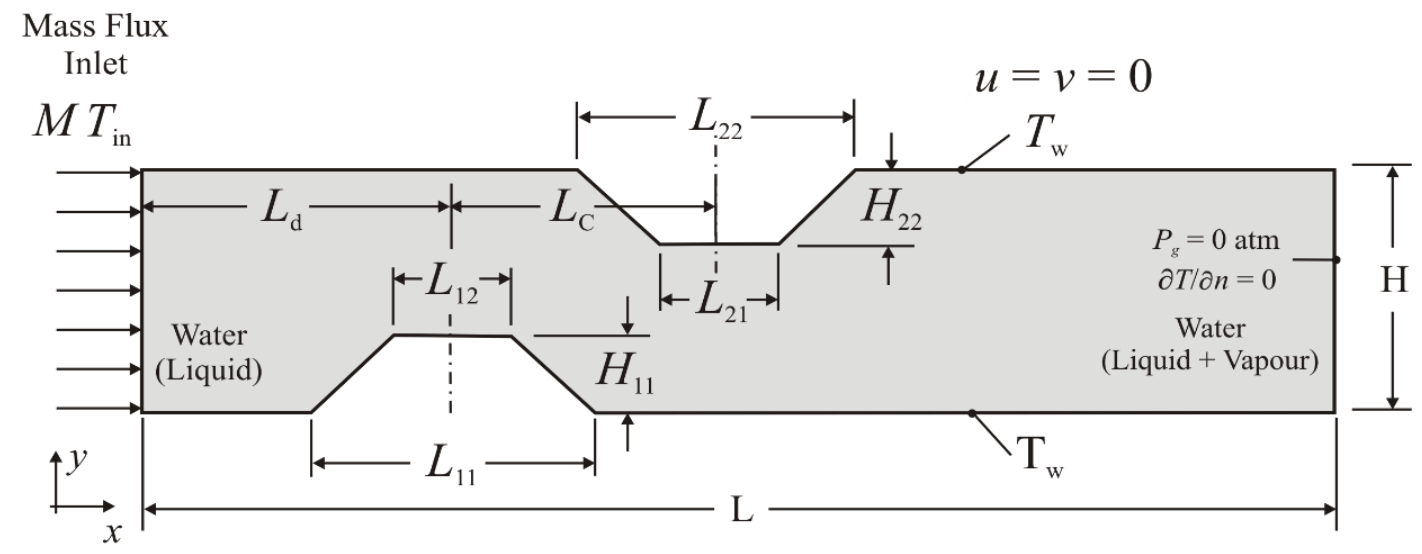

Figure 1. Computational domain of the microchannel with two heated trapezoidal blocks.

The microchannel has a length of $L=1.5 \mathrm{~mm}$, height of $H=0.1 \mathrm{~mm}, L_{d}=0.4 \mathrm{~mm}$ and $L_{c}=0.2 \mathrm{~mm}$. To evaluate the effects of the boiling process on the geometric evaluation, two different scenarios were simulated: with and without boiling. The two situations have the same parameters and boundary conditions set to the problem and all the geometries considered in this study were simulated in both cases, the only difference is that for the cases without the boiling process the multiphase and the phase change models were deactivated. Also, for each of the two cases, two different values of mass flux were considered: $M=1.0$ and $100.0 \mathrm{~kg} /\left(\mathrm{m}^{2} . \mathrm{s}\right)$, corresponding to the Reynolds numbers of $\operatorname{Re}_{H}=0.1$ and 10.0, respectively. The Reynolds number was calculated by (Bejan, 2013):

$\operatorname{Re}_{H}=\frac{M H}{\mu}$

where $\mu$ is the dynamic viscosity of the fluid $(\mathrm{kg} /(\mathrm{m} . \mathrm{s}))$.

The Constructal Design method is employed for the geometrical evaluation process of the microchannel, with the definition of four degrees of freedom and two constraints. The four degrees of freedom are the ratios between the height and higher width $\left(H_{11} / L_{11}, H_{22} / L_{22}\right)$ and between the lower and higher widths of both trapezoidal blocks $\left(L_{12} / L_{11}, L_{21} / L_{22}\right)$. The two constraints are the areas of the two blocks. Both are set to a constant value of $2,000 \mu \mathrm{m}^{2}$. The area of the two blocks can be calculated in the same way, as the area of block 1 (located on the lower surface) can be defined as:

$$
A_{B 1}=\frac{\left(L_{11}+L_{12}\right)}{2} \cdot H_{11}
$$

where $H_{11}$ is the height of the first block, $L_{11}$ is the higher width of the first block and $L_{12}$ is the lower width of the first block.

The main purpose of the present study is to investigate the influence of the height and higher width of the first block $\left(H_{11} / L_{11}\right)$ over the heat transfer rate $(q)$ and over the pressure drop $(\Delta P)$ for different magnitudes of the ratio between the lower width and higher width $\left(L_{12} / L_{11}\right)$. The objectives are the maximization of the heat transfer rate between the microchannel and the fluid and the minimization of the pressure drop in the microchannel. The heat transfer rate can be calculated as (Chen, 1966):

$$
q=h_{l} A_{S}\left(T_{W}-T_{i n}\right)+h_{N B} A_{S}\left(T_{W}-T_{s a t}\right)
$$

where $A_{s}$ is the surface area of the microchannel $\left(\mathrm{m}^{2}\right), h_{l}$ is the heat transfer coefficient for the liquid phase flowing alone in the microchannel $\left(\mathrm{W} / \mathrm{m}^{2} . \mathrm{K}\right)$ and $h_{N B}$ is the nucleate boiling heat transfer coefficient $\left(\mathrm{W} / \mathrm{m}^{2} . \mathrm{K}\right)$.

The pressure drop along the microchannel is calculated with:

$$
\Delta P=P_{\text {in }}-P_{\text {out }}
$$


where $P_{\text {in }}$ and $P_{\text {out }}$ are the averaged pressures in the inlet and outlet surfaces of the microchannel $(\mathrm{Pa})$, respectively.

The geometric optimization of the microchannel was done with the Exhaustive Search method, according to the defined degrees of freedom. In the present work, only the first block have its dimensions varied, the second block have a constant geometry in all simulations, defined by $H_{21} / L_{21}=0.50$ and $L_{22} / L_{21}=0.50$. Regarding the geometry of the first block, it varies in the range of $0.1 \leq L_{12} / L_{11} \leq 1.0$ for two different magnitudes of the ratio $H_{11} / L_{11}, H_{11} / L_{11}=0.1$ and 2.0. For these conditions, 40 simulations were performed.

The geometric evaluation of the first trapezoidal block was performed in two steps: firstly, one of the ratios $\left(L_{12} / L_{11}\right)$ was varied, keeping the other $\left(H_{11} / L_{11}\right)$ fixed. This step found a maximum value for the heat transfer rate, which was called the once maximized rate, $q_{1, \max }$, and, similarly, a minimum value was also found for the pressure drop between the inlet and outlet of the channel, $(\Delta P)_{1, \min }$. The geometries correspondent to these values were called the once thermally optimized geometry, $\left(L_{12} / L_{11}\right)_{\mathrm{o}, \mathrm{T}}$, and the once fluid dynamics optimized geometry, $\left(L_{12} / L_{11}\right)_{\mathrm{o}, \mathrm{F}}$. In the second step, the same process is repeated, now for all values of $H_{11} / L_{11}$. Among all the simulations, a maximum heat transfer rate value is found and is called the twice maximized, $q_{2, \max }$, and the same for the smallest pressure drop, called the twice minimized, $(\Delta P)_{2, \min }$. These values correspond to the geometries once optimized ratio $H_{11} / L_{11}$ for the thermal and fluid dynamics objectives, respectively, defined as: $\left(H_{11} / L_{11}\right)_{\mathrm{o}, \mathrm{T}}$ and $\left(H_{11} / L_{11}\right)_{\mathrm{o}, \mathrm{F}}$. Hence, it were obtained the twice optimized ratios $\left(L_{12} / L_{11}\right)_{\mathrm{oo}, \mathrm{T}}$ and $\left(L_{12} / L_{11}\right)_{\mathrm{oo}, \mathrm{F}}$. After, it was also performed a multi-objective analysis, were both performance indicators (thermal and fluid dynamics) were simultaneously considered with the aim of obtaining the optimum multi-objective geometry: $\left(L_{12} / L_{11}\right)_{\mathrm{oo}}$ and $\left(H_{11} / L_{11}\right)_{\mathrm{o}}$. It is worth mentioning that the main purpose is the comparison between the cases with and without boiling and its influence on the geometrical analysis. Therefore, the investigation of only two values for the second degree of freedom is enough for the present findings.

\subsection{Monophase Cases}

For the cases without boiling, it was solved the conservation equation of mass and the balance of momentum equations for modeling of monophase, laminar, two-dimensional and forced convective flows. The mass conservation equation is defined by (Bejan, 2013):

$$
\nabla \cdot \vec{V}=0
$$

where $\vec{V}$ is the velocity vector $(\mathrm{m} / \mathrm{s})$.

The momentum conservation equations in the $x$ and $y$ directions, respectively, are written as follows (Bejan, 2013):

$$
\nabla \cdot(\rho \vec{V} \vec{V})=-\nabla P+\nabla \cdot(\mu \nabla \vec{V})
$$

where $\rho$ is the density of the fluid $\left(\mathrm{kg} / \mathrm{m}^{3}\right), P$ is the pressure $(\mathrm{Pa}), \mu$ is the fluid dynamic viscosity $(\mathrm{kg} / \mathrm{m} \cdot \mathrm{s})$.

The energy conservation equation is written as (Bejan, 2013):

$$
\nabla \cdot(\overrightarrow{V T})=\nabla \cdot(\lambda \nabla T)
$$

where $T$ is the temperature $(\mathrm{K})$ and $\lambda$ is the thermal diffusivity of the fluid $\left(\mathrm{m}^{2} / \mathrm{s}\right)$.

\subsection{Multiphase Cases}

In the present study, the Mixture multiphase model was employed to simulate the interaction between the two phases (liquid and vapor) in the cases where boiling happens. The Mixture is a simplified version of the Eulerian model, which considers the phases as interpenetrating. It calculates the conservation equations for the mixture of the phases and the equation of the volume fraction for the secondary phases. It also has algebraic expressions for the relative and drift velocities. More details about the Mixture multiphase model can be seen in the work of Manninen et al. (1996).

The continuity conservation equation for the Mixture model is given by (Bejan, 2013):

$$
\nabla \cdot\left(\rho_{m} \vec{V}_{m}\right)=0
$$

where $\rho_{m}$ is the mixture density $\left(\mathrm{kg} / \mathrm{m}^{3}\right)$ and $\vec{V}_{m}$ is the mass-averaged velocity $(\mathrm{m} / \mathrm{s})$, also known as the mixture velocity, which are given, respectively, by: 


$$
\begin{aligned}
& \rho_{m}=\sum_{k=1}^{n} \alpha_{k} \rho_{k} \\
& \vec{V}_{m}=\frac{\sum_{k=1}^{n} \alpha_{k} \rho_{k} \vec{V}_{k}}{\rho_{m}}
\end{aligned}
$$

where $n$ is the number of phases, $\alpha_{k}, \rho_{k}$ and $\vec{V}_{k}$ are the volume fraction, density $\left(\mathrm{kg} / \mathrm{m}^{3}\right)$ and velocity $(\mathrm{m} / \mathrm{s})$ of phase $k$.

The balance of momentum equation is defined as (Manninen et al., 1996):

$$
\nabla \cdot\left(\rho_{m} \vec{V}_{m} \vec{V}_{m}\right)=-\nabla p+\nabla \cdot\left(\mu_{m} \nabla \vec{V}_{m}\right)+\rho_{m} \vec{g}+\vec{F}-\nabla \cdot\left(\sum_{k=1}^{n} \alpha_{k} \rho_{k} \vec{V}_{d r, k} \vec{V}_{d r, k}\right)
$$

where $p$ is the pressure $(\mathrm{Pa}), \vec{F}$ is a body force $\left(\mathrm{N} / \mathrm{m}^{3}\right), \vec{g}$ is the gravity acceleration $\left(\mathrm{m} / \mathrm{s}^{2}\right)$ and $\mu_{m}$ is the dynamic viscosity of the mixture $\left(\mathrm{N} \cdot \mathrm{s} / \mathrm{m}^{2}\right) . \vec{V}_{d r, k}$ is the drift velocity for secondary phase $k(\mathrm{~m} / \mathrm{s})$, representing the difference between the velocity of phase $k$ and the mixture velocity:

$$
\vec{V}_{d r, k}=\vec{V}_{k}-\vec{V}_{m}
$$

The energy conservation equation for the mixture can be written as (Manninen et al., 1996):

$$
\nabla \cdot \sum_{k=1}^{n}\left[\alpha_{k} \vec{V}_{k}\left(\rho_{k} E_{k}+p\right)\right]=\nabla \cdot\left(k_{e f f} \nabla T\right)+S_{E}
$$

where $k_{e f f}$ is the effective conductivity $\left(\sum \alpha_{k} k_{k}\right), k_{k}$ is the thermal conductivity of phase $k(\mathrm{~W} / \mathrm{m} \cdot \mathrm{K}), S_{E}$ is a source term relative to any volumetric heat sources. For a compressible phase, the energy term $E_{k}(\mathrm{~J})$ is given by (Manninen et al., 1996):

$$
E_{k}=h_{k}-\frac{p}{\rho_{k}}+\frac{V_{k}^{2}}{2}
$$

and $E_{k}=h_{k}$ and for an incompressible phase, where $h_{k}$ is the sensible enthalpy for phase $k(\mathrm{~J})$.

In the Mixture model, an additional transport equation is solved to take into account the volume fraction. This equation is expressed based on the continuity conservation equation for the secondary phase and for a primary phase named $q$ and a secondary named $p$, it can be written as (Manninen et al., 1996):

$$
\nabla \cdot\left(\alpha_{p} \rho_{p} \vec{V}_{m}\right)=-\nabla \cdot\left(\alpha_{p} \rho_{p} \vec{V}_{d r, p}\right)+\sum_{q=1}^{n}\left(\dot{m}_{q p}-\dot{m}_{p q}\right)
$$

where $\dot{m}_{q p}, \dot{m}_{p q}$ are the rates of mass transfer between the phases $\left(\mathrm{kg} / \mathrm{m}^{3} \cdot \mathrm{s}\right)$.

One particularity of the Mixture model is the way it calculates the velocity of the phases. It takes into account the drift velocity and the relative velocity (also known as slip velocity), which is defined as the relative velocity between two phases (Manninen et al., 1996):

$$
\vec{V}_{p q}=\vec{V}_{p}-\vec{V}_{q}
$$

It is clear that the problem with Eq. (16) is that the velocities of the phases are unknown at principle and because of that, the relative velocity needs to be expressed in an algebraic expression, given by (Manninen $e t$ al., 1996): 


$$
\vec{V}_{p q}=\frac{\tau_{p}}{f_{\text {drag }}} \frac{\left(\rho_{p}-\rho_{m}\right)}{\rho_{p}} \vec{a}
$$

where $\tau_{p}$ is the particle relaxation time (s), $d_{p}$ is the diameter of the particles (or droplets or bubbles) of secondary phase $(\mathrm{m}), \vec{a}$ is the secondary phase acceleration of the particle $\left(\mathrm{m} / \mathrm{s}^{2}\right)$. The default drag function $f_{\text {drag }}$ is defined by the correlation of Schiller \& Naumann (1935):

$$
f_{\text {drag }}= \begin{cases}1+0.15 \operatorname{Re}^{0.687} & \operatorname{Re} \leq 1,000 \\ 0.0183 \operatorname{Re} & \operatorname{Re}>1,000\end{cases}
$$

The Reynolds number in Eq. (18) is calculated based on the relative velocity, $\vec{V}_{p q}$ (Manninen et al., 1996):

$$
\operatorname{Re}=\frac{d_{p} \rho_{p}\left|\vec{V}_{p q}\right|}{\mu_{p}}
$$

Now, from Eq. (10), (12) and (16), it is possible to formulate a relation between the relative and the drift velocities:

$$
\vec{V}_{d r, p}=\vec{V}_{p q}-\sum_{k=1}^{n} c_{k} \vec{V}_{k q}
$$

where $c_{k}$ is the mass fraction for any phase $(k)$ and is defined as:

$$
c_{k}=\frac{c_{k} \rho_{k}}{\rho_{m}}
$$

In the case of a problem with only two phases, Eq. (20) can be written in a simpler manner:

$$
\vec{V}_{d r, p}=\vec{V}_{p q}\left(1-c_{p}\right)
$$

Along with the Mixture model, the present study employed the Lee model (Lee, 1980) to simulate the boiling process. This model is governed by an equation that takes into account the heat transfer from both the liquid to vapor (evaporation) and vapor to liquid (condensation) phases:

$$
\nabla \cdot\left(\alpha_{v} \rho_{v} \vec{V}_{v}\right)=\dot{m}_{l v}-\dot{m}_{v l}
$$

where $v$ and $l$ represent, respectively, the vapor and liquid phases, $\dot{m}_{l}$ and $\dot{m}_{v l}$ are, respectively, the rates of mass transfer due to evaporation and condensation $\left(\mathrm{kg} / \mathrm{m}^{3} \cdot \mathrm{s}\right)$. They are given by (Lee, 1980):

$$
\begin{aligned}
& \left\{\begin{array}{cc}
\dot{m}_{l v}=\operatorname{coef} f * \alpha_{l} \rho_{l} \frac{\left(T_{l}-T_{s a t}\right)}{T_{\text {sat }}} & \text { If } T_{l} \geq T_{\text {sat }} \text { (evaporation) } \\
\dot{m}_{l v}=0 & \text { If } T_{l}<T_{\text {sat }}
\end{array}\right. \\
& \left\{\begin{array}{cc}
\dot{m}_{v l}=\operatorname{coef} f * \alpha_{v} \rho_{v} \frac{\left(T_{s a t}-T_{v}\right)}{T_{s a t}} & \text { If } T_{v} \leq T_{s a t} \text { (condensation) } \\
\dot{m}_{v l}=0 & \text { If } T_{v}>T_{s a t}
\end{array}\right.
\end{aligned}
$$

where coef $f$ is the time relaxation parameter for the model of Lee $\left(\mathrm{s}^{-1}\right)$.

\section{Numerical Modeling}

The present study employed a FVM based software, ANSYS Fluent ${ }^{\mathrm{TM}} 14.5$, to resolve the numerical simulations. The SIMPLE algorithm was used for pressure-velocity coupling. A Green-Gauss Cell Based 
gradient and the QUICK method were used for the momentum, energy and volume fraction equations. For pressure, Body Force Weighted spatial discretization was used. All the simulations performed in this study were carried out in a steady state regime and the residuals were considered converged when reaching the value of $1.0 \times 10^{-5}$ for continuity, $1.0 \times 10^{-6}$ for velocities and volume fraction and $1.0 \times 10^{-7}$ for energy.

To define the grid to be used in the simulations, a mesh independence study was carried out considering the most complex geometry in terms of the simulation $\left(H_{11} / L_{11}=2.0\right.$ and $L_{12} / L_{11}=1.0$ with $\operatorname{Re}_{H}=10.0$ and phase change enabled), as shown in Table 1. Considering the mesh as independent when the relative deviation of the heat transfer rate between two successive meshes was less than $0.03 \%\left(R=\left|\left(q^{j}-q^{j+l}\right) / q^{j}\right|<3.0 \times 10^{-4}\right.$, it was observed that the mesh with 38,382 finite volumes achieved this criterion. It was also observed that a mesh with triangular volumes and extra refinement closer to the walls (Figure 2) was able to provide better convergence as it captured better the heat transfer phenomenon, especially in the cases with phase change.

Table 1. Mesh independence study.

\begin{tabular}{c|c|c}
\hline Number of Volumes & $q(\mathrm{~W})$ & Relative Deviation \\
\hline 7,595 & $6,165.700$ & 0.01629 \\
12,275 & $6,065.214$ & 0.00427 \\
16,150 & $6,039.288$ & 0.00997 \\
21,046 & $5,979.053$ & 0.00366 \\
27,630 & $6,000.921$ & 0.00144 \\
$\mathbf{3 8 , 3 8 2}$ & $\mathbf{6 , 0 0 9 . 5 7 1}$ & $\mathbf{0 . 0 0 0 2 4}$ \\
49,811 & $6,011.021$ & - \\
\hline
\end{tabular}
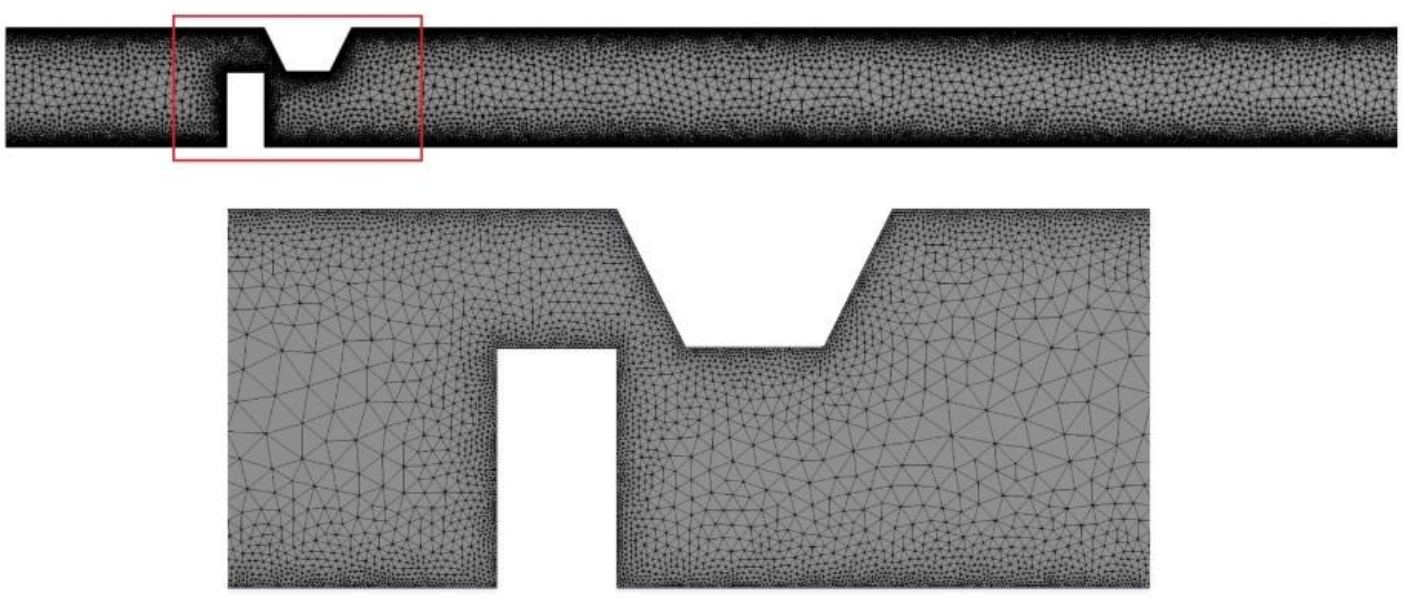

Figure 2. Mesh with triangular finite volumes employed in the present study.

To verify the numerical model employed in this study, a comparison was made with the results obtained in the numerical work of Vivekanand \& Raju (2015), where a similar microchannel, with 0.1 and $1.0 \mathrm{~mm}$ of height and length, respectively, and without the trapezoidal blocks, was subjected to laminar boiling flows. Authors studied the microchannel in two different situations: with fixed temperature in the walls and with constant heat flux in the walls. The comparison of the vapor volume fraction generated along the microchannel can be seen in Figure 3 for the case with prescribed temperature in the walls and constant heat flux, Figure 3(a) and 3(b), respectively. It can be seen that the present study was able to achieve results very similar to those of Vivekanand \& Raju (2015), with differences of less than $4 \%$ being observed in the two cases. It is worth mentioning that the difference in the modeling of Vivekanand \& Raju (2015) in comparison with the present model is the use of Volume of Fluid (VOF) method to tackle with the two phase flow Therefore, the model employed in this study is considered adequate to simulate microchannels subjected to boiling flows in the laminar regime. 


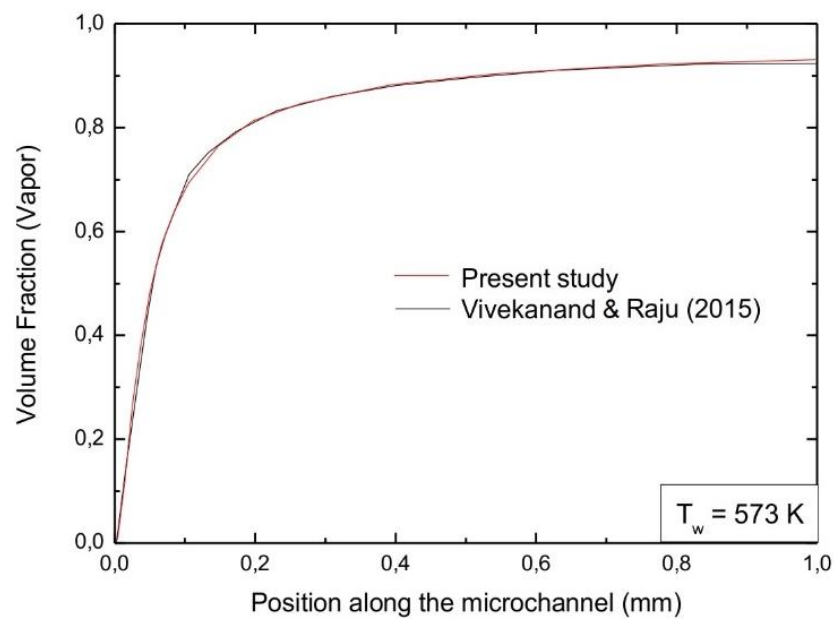

(a)

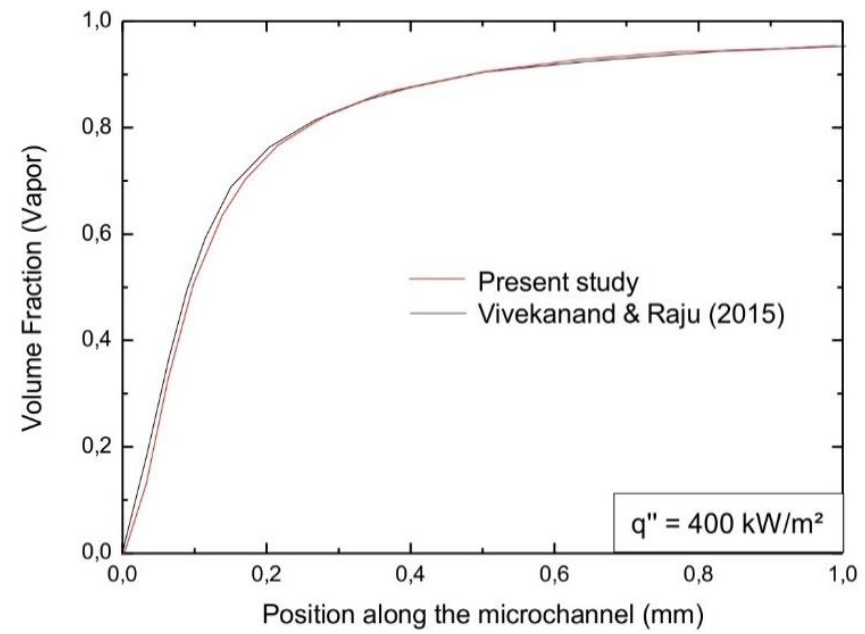

(b)

Figure 3. Verification of the model employed in this study with that of Vivekanand \& Raju (2015): a) case study with prescribed temperature at the channel walls, b) case study with prescribed heat flux.

\section{Results and Discussion}

In this study, the results are presented in three steps: first, a thermal analysis is done, after that, a fluid dynamics analysis, and then, a multi-objective analysis. In each evaluation, it is shown the influence of the geometry $\left(H_{11} / L_{11}\right.$ and $\left.L_{12} / L_{11}\right)$ over the defined performance indicators, for $\operatorname{Re}_{H}=0.1$ and 10.0 , and it is also shown the comparison between the approaches with and without boiling.

\subsection{Thermal Analysis}

The thermal analysis is done considering only the thermal purpose: the maximization of the heat transfer rate $(q)$. Hence, the geometry that has the highest value of heat transfer rate is considered the optimal thermal geometry. The influence of $L_{12} / L_{11}$ over the heat transfer rate, for different values of $H_{11} / L_{11}$, can be seen in Figure 4. It can be observed that the cases without boiling were able to generate slightly more heat transfer than the cases where the boiling process happened. It was noticed a difference in the heat transfer rate of around $1.5 \%$ between the cases with and without boiling for $\operatorname{Re}_{H}=0.1$ and between 1.6 and $2.1 \%$ for $\operatorname{Re}_{H}=10.0$. The main reason for this behavior can be associated with the low intensity of the fluid flow for the present conditions, which does not carry the formed vapor from the microchannel walls, generating a small region where the vapor acts as a thermal insulator in the wall. For flows with higher intensity, it is expected that this tendency will change, with boiling flows leading to higher magnitudes of heat transfer rate. 


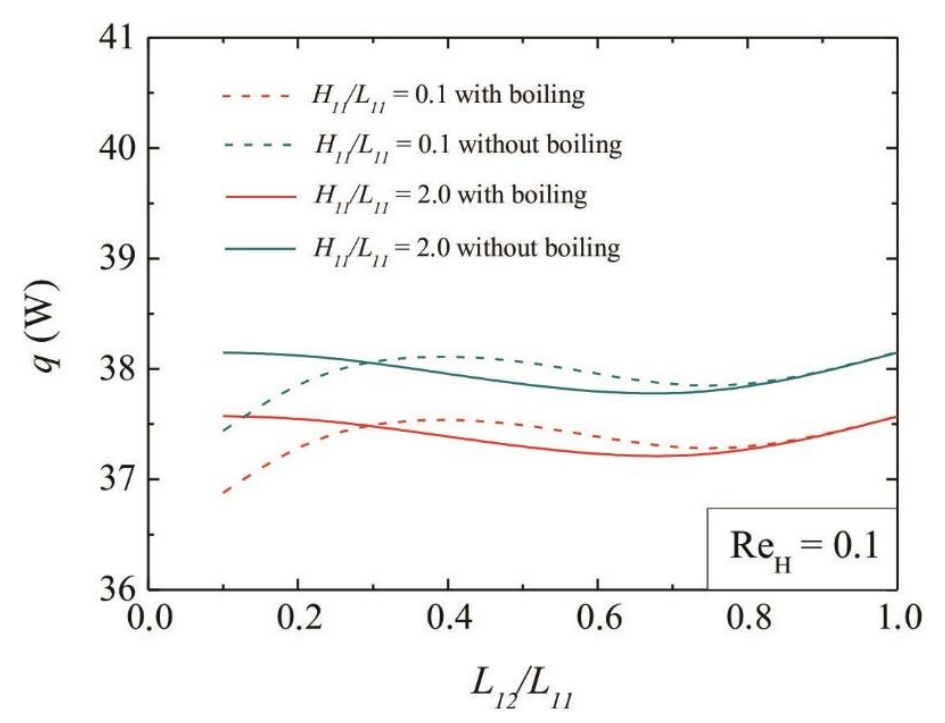

(a)

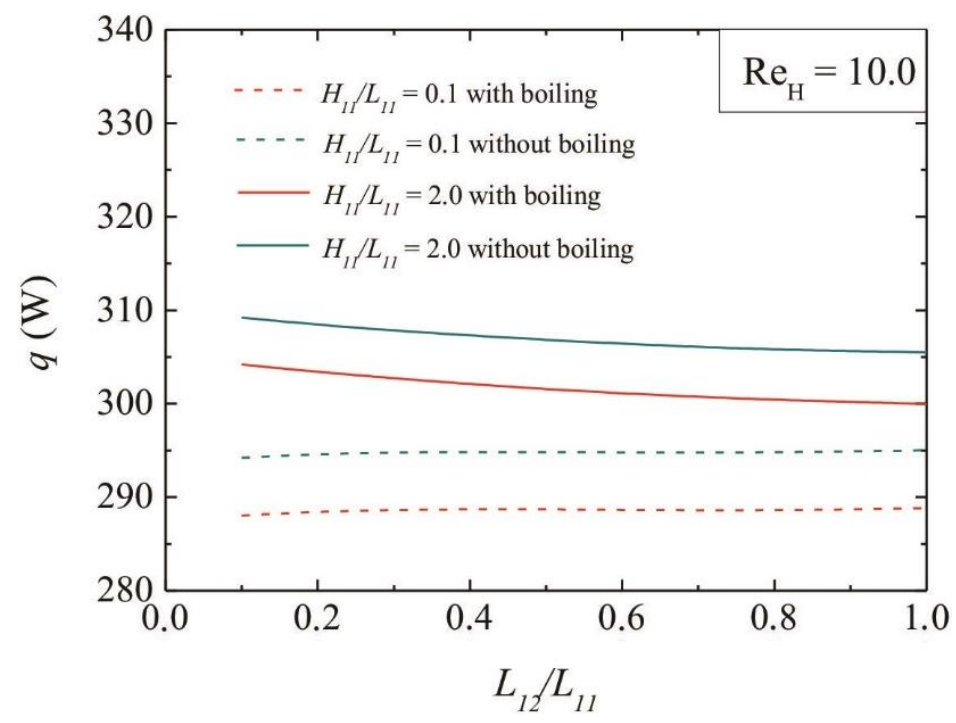

(b)

Figure 4. Effect of $L_{12} / L_{11}$ over the heat transfer rate $(q)$ for different values of $H_{11} / L_{11}$ and Reynolds number: (a) $\operatorname{Re}_{H}=0.1$; (b) $\operatorname{Re}_{H}=10.0$.

Concerning the geometric analysis, there is no difference in the behavior of the effect of the ratio $L_{12} / L_{11}$ over the heat transfer rate $(q)$ for the cases with and without boiling, i.e., for the present conditions the consideration of boiling does not led to different geometrical recommendations in comparison with the cases where boiling is disregarded.

Regarding the mass flux, it can be seen that in $\operatorname{Re}_{H}=10.0$, a more noticeable difference in the heat transfer rate is observed for the two values of $H_{11} / L_{11}$ in comparison to the results obtained for $\operatorname{Re}_{H}=0.1$. Also, for $\operatorname{Re}_{H}$ $=10.0, L_{12} / L_{11}$ has almost no effect over the heat transfer for $H_{11} / L_{11}=0.1$. The highest differences between the best and worst cases are nearly $1.9 \%$ and $5.1 \%$ for $\operatorname{Re}_{H}=0.1$ and 10.0 , respectively, for the cases without boiling, and of $1.9 \%$ and $5.6 \%$ for the cases with boiling.

From these results, it was possible to obtain the values of the optimal geometries concerning the thermal purpose. For the cases without boiling, they were $\left(H_{11} / L_{11}\right)_{\mathrm{o}, \mathrm{T}}=2.0$ and $\left(L_{12} / L_{11}\right)_{\mathrm{oo}, \mathrm{T}}=0.1$, the same for both values of $\operatorname{Re}_{H}$, with a $q_{2, \max }=38.149 \mathrm{~W}$ and $q_{2, \max }=309.199 \mathrm{~W}$ for $\operatorname{Re}_{H}=0.1$ and 10.0 , respectively. For the 
cases with boiling, the optimal thermal geometries were exactly the same as in the cases without boiling, with $q_{2, \max }=37.573 \mathrm{~W}$ and $q_{2, \max }=304.206 \mathrm{~W}$ for $\operatorname{Re}_{H}=0.1$ and 10.0 , respectively.

Figure 5 shows the temperature fields for the optimal thermal geometries without boiling (a) and with boiling (b) and also the vapor volume fraction field for the case with boiling (c). It can be seen that there are no significant differences between the two situations. In both cases, the geometry with the highest value of $H_{11} / L_{11}$ proved to be the best for increasing heat transfer. It is visible that the higher height of the first block forced the fluid to have a greater interaction with the heated walls of the microchannel. It also can be noted from Figure 5 (c) that in the cases with boiling, the vapor was being generated closer to the walls with an important contribution of the two trapezoidal blocks. The highest magnitudes of vapor volume fraction are reached in the regions of lower basis of the two trapezoidal blocks. Specifically for the present conditions, the vapor generation in stagnation regions of the trapezoidal blocks led to the insulation of the wall and meagered of heat transfer rate.

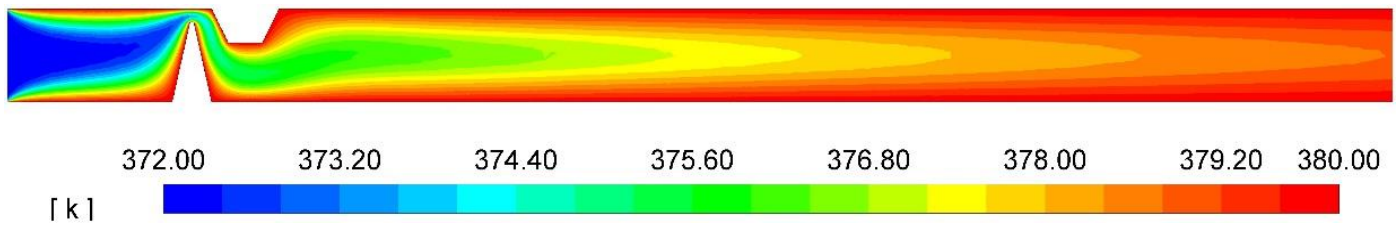

(a)

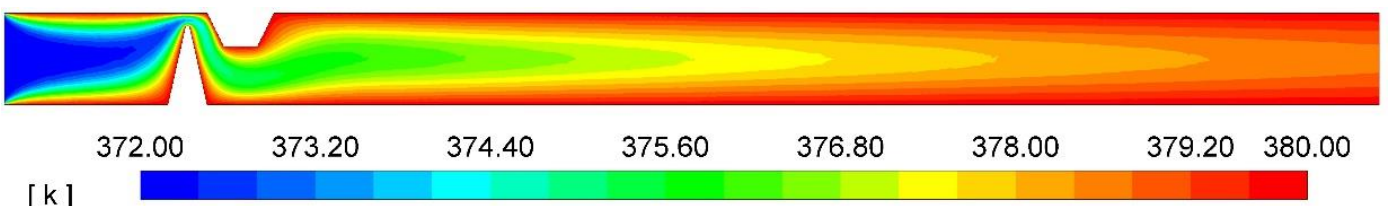

(b)

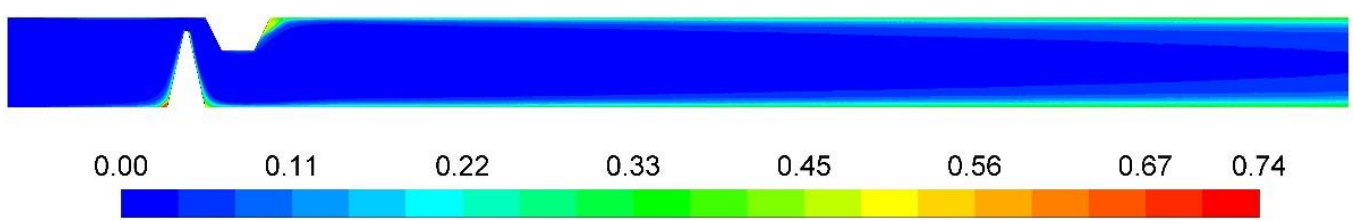

(c)

Figure 5. Temperature (K) fields for $\operatorname{Re}_{H}=10.0, L_{12} / L_{11}=0.1$ and $H_{11} / L_{11}=2.0$ : (a) without boiling; (b) with boiling; (c) vapor volume fraction field for the case with boiling.

\subsection{Fluid Dynamics Analysis}

The fluid dynamics analysis is done considering the difference in the pressures between the inlet and the outlet, i.e., the pressure drop along the microchannel $(\Delta P)$, as the performance indicator. The purpose is to determine the optimal fluid dynamics geometry, the one with the lowest value of pressure drop. Figure 6 shows the results for $\operatorname{Re}_{H}=0.1$ (a) and 10.0 (b), with the influence of $L_{12} / L_{11}$ over the pressure drop, for different values of $H_{11} / L_{11}$. Similar to what was observed in the thermal analysis, there was no difference in the behavior of the effect of the geometry over the pressure drop between the cases with and without boiling. Nevertheless, now the best results are from the cases with the boiling process enabled. Probably, this behavior can be associated with the generation of some portion of vapor, which is lighter than the monophase water, being transported in more easy way. It can be seen that differences in the pressure drop between with and without boiling decreased significantly from $\operatorname{Re}_{H}=0.1$ to $R_{\mathrm{H}}=10.0$, although the cases with boiling were still able to perform better than those without boiling for any geometry simulated in the present study. Regarding the differences in the pressure drop, they stayed between 31 and $44 \%$ comparing the cases with and without boiling for $\operatorname{Re}_{H}=0.1$ and between 3.1 and $5.5 \%$ for $\operatorname{Re}_{H}=10.0$, considerably higher than those differences observed in the thermal analysis. 


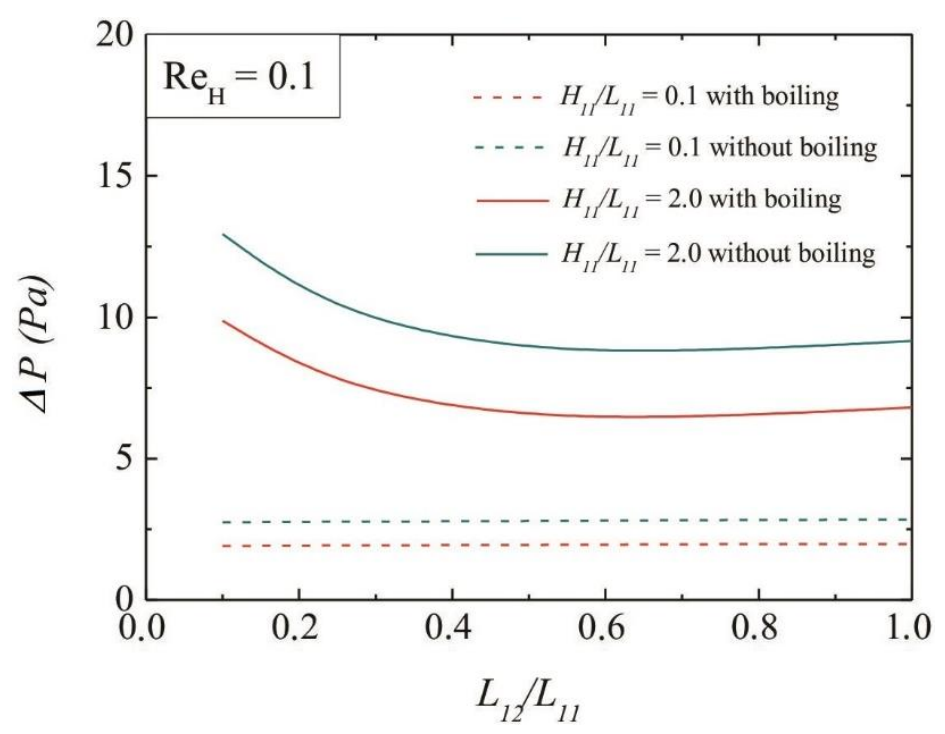

(a)

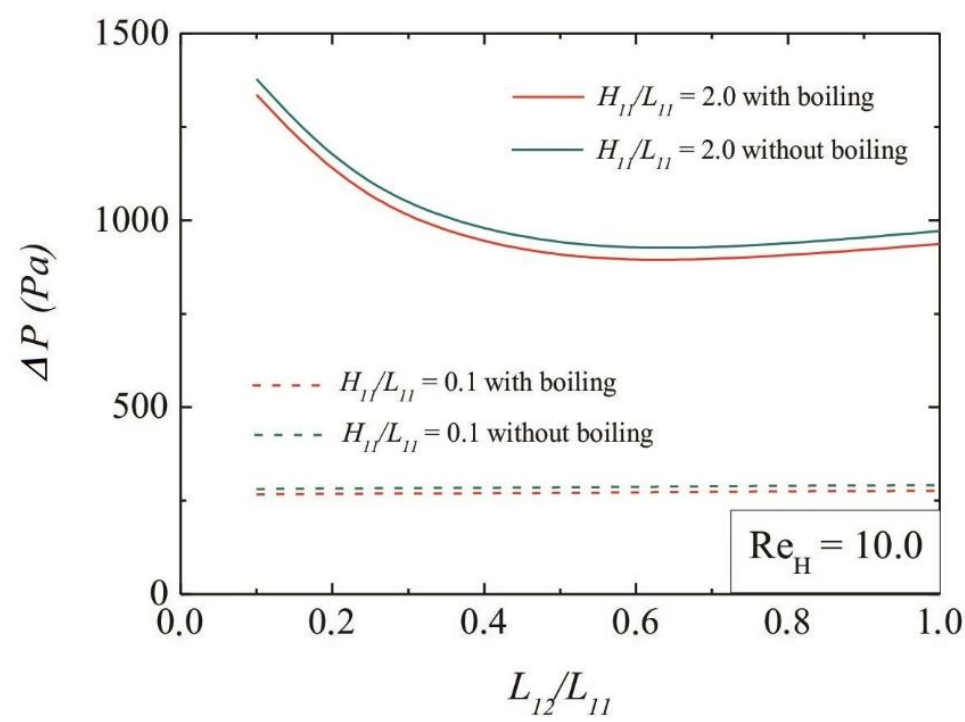

(b)

Figure 6. Effect of $L_{12} / L_{11}$ over the pressure drop $(\Delta P)$ for different values of $H_{11} / L_{11}$ and Reynolds number: (a) $\operatorname{Re}_{H}=0.1$; (b) $\operatorname{Re}_{H}=10.0$.

One can also observe in Figure 6 that $L_{12} / L_{11}$ has almost no effect in the pressure drop for $H_{11} / L_{11}=0.1$ but has a significant influence when $H_{11} / L_{11}=2.0$, where the first block has much higher height. For $H_{11} / L_{11}=2.0$, an optimal geometry is obtained with an intermediate value of $L_{12} / L_{11}=0.5$ for both $\operatorname{Re}_{H}=0.1$ and 10.0. The best fluid dynamics cases were 5.01 and 5.17 times better than the worst cases, for $\operatorname{Re}_{H}=0.1$ and 10.0 , respectively, for the cases without boiling, and 4.71 and 4.90 times better for the cases with boiling, notably higher than what was seen in the thermal analysis.

From these results, the values of the optimal fluid dynamics geometries were, for the cases without boiling, $\left(H_{11} / L_{11}\right)_{\mathrm{o}, \mathrm{F}}=0.1$ and $\left(L_{12} / L_{11}\right)_{\mathrm{oo}, \mathrm{F}}=0.1$, the same for both values of $\operatorname{Re}_{H}$, with a $(\Delta P)_{2, \min }=2.75 \mathrm{~Pa}$ and $(\Delta P)_{2, \text { min }}$ $=281.30 \mathrm{~Pa}$ for $\mathrm{Re}_{H}=0.1$ and 10.0 respectively. As occurred in the thermal analysis, for the cases with boiling, the optimal fluid dynamics geometries were the same as in the cases without boiling, with $(\Delta P)_{2, \min }=1.91 \mathrm{~Pa}$ and $(\Delta P)_{2, \min }=266.63 \mathrm{~Pa}$ for $R e_{\mathrm{H}}=0.1$ and 10.0 , respectively.

Figure 7 shows the velocity and pressure fields for the optimal fluid dynamics geometries without (a) and with boiling (b). It can be seen that in the case without boiling, the highest value of the flow velocity is located 
between the two trapezoidal blocks and is about $0.0023 \mathrm{~m} / \mathrm{s}$. After passing through the two blocks, the fluid keeps an almost constant velocity profile. In the case with boiling, an acceleration is also observed around the two blocks, although with a higher velocity (about $0.0037 \mathrm{~m} / \mathrm{s}$ ). For the case with boiling, the flow has a further increase in its velocity along the whole microchannel that continues to accelerate up until the outlet. This fact reduces the pressure drop in the microchannel, increasing the fluid dynamics performance. This behavior can be credited to the much lower density of the vapor phase, which has an effect of increasing the fluid velocity, and is normally seen in boiling flows. Also, the gap in the results of the pressure drop observed between the two values of $H_{11} / L_{11}$, in both with and without boiling cases, happened due to the stricture effect occurred in the flow for $H_{11} / L_{11}=2.0$. The constraint cause a significant increase in the velocity and in the pressure in that region, which decreased the fluid dynamics performance for those geometries compared to $H_{11} / L_{11}=0.1$.

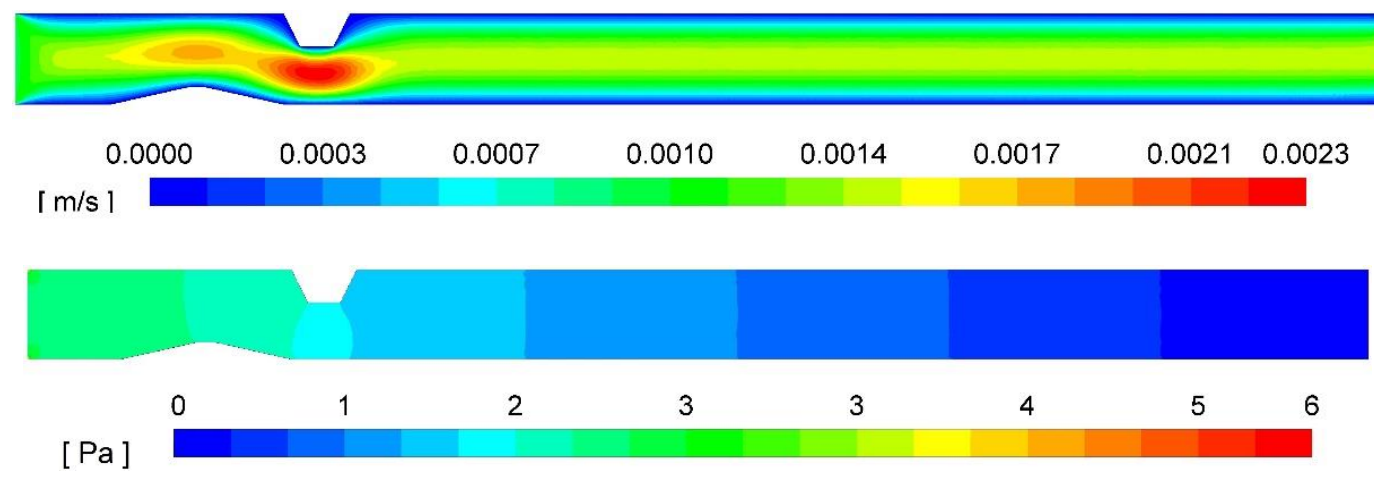

(a)
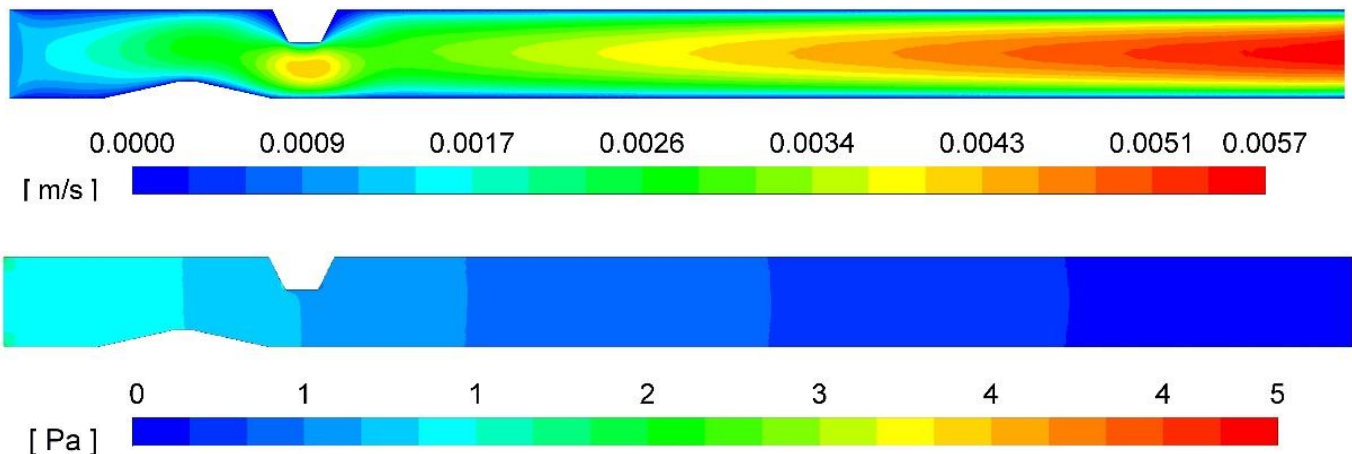

(b)

Figure 7. Velocity (m/s) and Pressure (Pa) fields for $\operatorname{Re}_{H}=0.1, L_{12} / L_{11}=0.1, H_{11} / L_{11}=0.1$ and: (a) without boiling; (b) with boiling.

\subsection{Multi-objective Analysis}

The final part of the geometric evaluation process is carried out considering simultaneously the two performance indicators in order to determine the optimum multi-objective geometry. To do so, the graphics presented in Figure 8 were plotted considering the results obtained for the pressure drop $(\Delta P)$ as a function of the inverse of the heat transfer rate $(q)$ results. Therefore, the optimal multi-objective geometries are those which the point in the graphic is closer to the point where both axes are equal to zero, which represents an idealized problem with minimum pressure drop and maximum heat transfer rate. As can be seen in Figure 8, the optimal geometries with $H_{11} / L_{11}=0.1$ proved to have a considerable higher multi-objective performance compared to those with $H_{11} / L_{11}=2.0$, for both mass fluxes and boiling conditions. It is also possible to note that the heat transfer rate is almost unaffected by $H_{11} / L_{11}$ for $\operatorname{Re}_{H}=0.1$. For $\operatorname{Re}_{H}=10.0, H_{11} / L_{11}$ seems to have some effect over heat transfer rate, though still much lower than that of the pressure drop. Overall, this multiobjective analysis showed that the defined degrees of freedom had a much greater influence over pressure drop than over the heat transfer rate. 


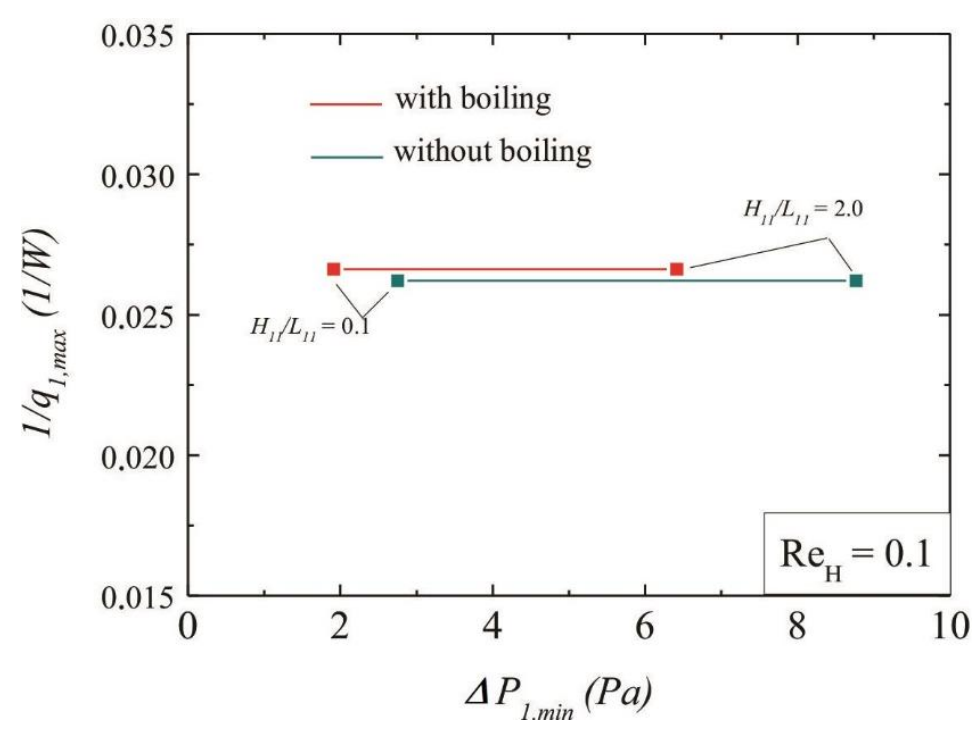

(a)

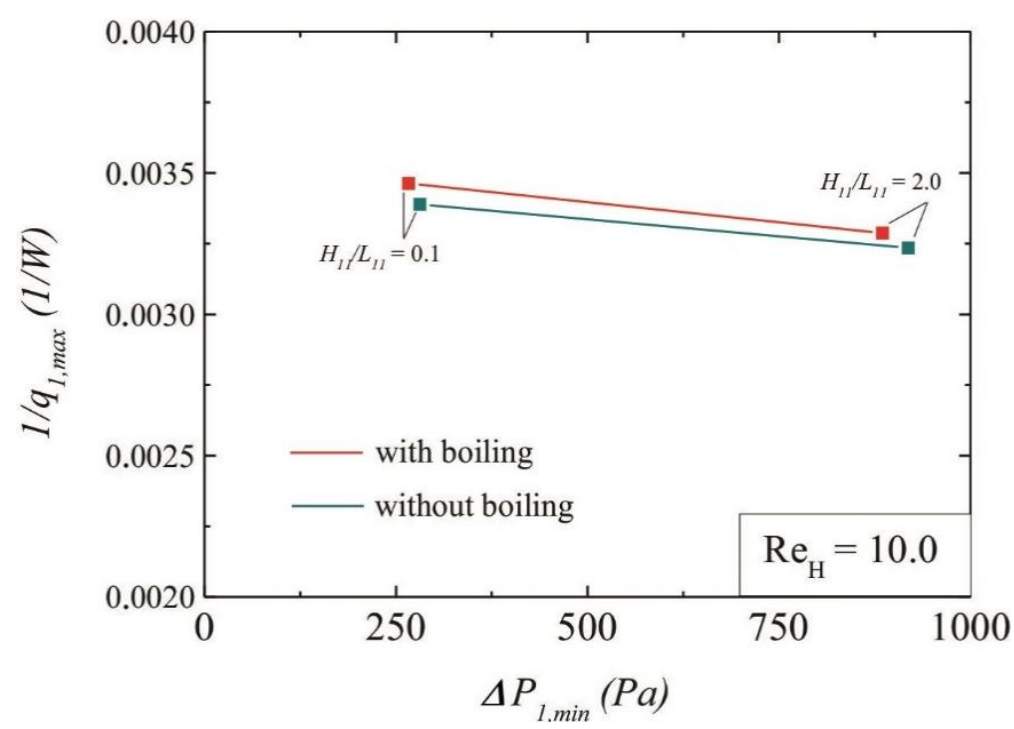

(b)

Figure 8. Effect of the once minimized pressure drop $(\Delta P)_{1, \min }$ over the inverse of the once maximized heat transfer $\left(1 /(q)_{1, \max }\right)$ for different values of $H_{11} / L_{11}$ and Reynolds number: (a) $\operatorname{Re}_{H}=$

$$
0.1 \text {; (b) } \operatorname{Re}_{H}=10.0 \text {. }
$$

Table 2 shows a compilation of the overall optimal multi-objective geometries from the results obtained in this study, $\left(H_{11} / L_{11}\right)_{\mathrm{o}}$, and $\left(L_{12} / L_{11}\right)_{\mathrm{oo}}$. The optimal geometries found for both $\mathrm{Re}_{H}$ for the cases with and without boiling were the same, i.e., the one with the lowest values of $H_{11} / L_{11}$ and $L_{12} / L_{11}$ between all geometries evaluated in this study, and is also the same optimal geometry considering only the fluid dynamics objective. 
Table 2. Optimal shapes for multi-objective problem

\begin{tabular}{ccccc}
\hline & \multicolumn{2}{c}{ Cases without boiling } & \multicolumn{2}{c}{ Cases with boiling } \\
\cline { 2 - 5 } $\boldsymbol{R}_{\mathbf{H}}$ & $\mathbf{0 . 1}$ & $\mathbf{1 0 . 0}$ & $\mathbf{0 . 1}$ & $\mathbf{1 0 . 0}$ \\
\hline$\left(\boldsymbol{H}_{11} / \boldsymbol{L}_{11}\right)_{\mathbf{0}}$ & 0.1 & 0.1 & 0.1 & 0.1 \\
$\left(\boldsymbol{L}_{12} / \boldsymbol{L}_{11}\right)_{\mathbf{0 o}}$ & 0.1 & 0.1 & 0.1 & 0.1 \\
$\boldsymbol{H}_{\boldsymbol{1 1}}$ & $19.07 \mu \mathrm{m}$ & $19.07 \mu \mathrm{m}$ & $19.07 \mu \mathrm{m}$ & $19.07 \mu \mathrm{m}$ \\
$\boldsymbol{L}_{\boldsymbol{1 1}}$ & $190.69 \mu \mathrm{m}$ & $190.69 \mu \mathrm{m}$ & $190.69 \mu \mathrm{m}$ & $190.69 \mu \mathrm{m}$ \\
$\boldsymbol{L}_{12}$ & $19.07 \mu \mathrm{m}$ & $19.07 \mu \mathrm{m}$ & $19.07 \mu \mathrm{m}$ & $19.07 \mu \mathrm{m}$ \\
\hline
\end{tabular}

\section{Conclusions}

The present study performed numerical simulations of a microchannel with two trapezoidal blocks, subjected to convective boiling water flows, applying the Constructal Design method and Exhaustive Search to the geometrical evaluation of the microchannel. To investigate the influence of the boiling process over the geometrical evaluation, two different cases were evaluated: with and without boiling. Furthermore, each of those two situations were divided again into two different values of mass flux, 1.0 and $100.0 \mathrm{~kg} /\left(\mathrm{m}^{2} \cdot \mathrm{s}\right)$, corresponding to $\operatorname{Re}_{H}=0.1$ and 10.0, respectively. In this study, it was investigated the influence of the height and higher width of the first block $\left(H_{11} / L_{11}\right)$ over the heat transfer rate $(q)$ and the pressure drop $(\Delta P)$ for different magnitudes of the ratio between the lower width and higher width of the trapezoidal block $\left(L_{12} / L_{11}\right)$. The geometry of the second block was kept constant throughout all simulations. The purposes of the geometric evaluation were to find geometries that would maximize the heat transfer rate $(q)$ and minimize the pressure drop $(\Delta P)$. Thermal and fluid dynamics analyzes were carried out, as well as a multi-objective analysis.

The results showed that, for the conditions applied in the present study, the boiling process decreased the heat transfer rate approximately $1.6 \%$ for $\mathrm{Re}_{H}=0.1$ and between 1.6 and $2.1 \%$ for $\mathrm{Re}_{H}=10.0$, which was not intuitively expected in a first moment. This behavior can be related with the generation of vapor near the microchannel surfaces, mainly in the region of higher width of the trapezoidal blocks, where the fluid is stagnated due to low magnitude of Reynolds number. Despite of some differences in the magnitude of $q$, the presence of the boiling process did not generate any significant behavior change of the effect of the geometry $\left(H_{11} / L_{11}\right.$ and $\left.L_{12} / L_{11}\right)$ over the heat transfer rate. The best thermal performance was obtained for the highest intrusion of the trapezium in the channel, $\left(H_{11} / L_{11}\right)_{\mathrm{o}, \mathrm{T}}=2.0$ and lowest ratio $\left(L_{12} / L_{11}\right)_{\mathrm{oo}, \mathrm{T}}=0.1$ for the cases with and without boiling.

The fluid dynamics analysis showed a better performance for cases with the boiling process enabled, especially for $\mathrm{Re}_{H}=0.1$. In general, the differences in the results obtained for the pressure drop between the cases with and without boiling were between 31 and $44 \%$ for $\operatorname{Re}_{H}=0.1$ and between 3.1 and $5.5 \%$ for $\operatorname{Re}_{H}=$ 10.0, considerably higher than those differences observed in the thermal analysis. From the velocity fields, it was also possible to visualize that the fluid velocity profile along the microchannel accelerates in the cases with the boiling process, which does not happen in the cases without boiling. This was attributed to the much lower density of the vapor phase that tends to accelerate the whole fluid along microchannel, as it normally happens in boiling flows inside channels and microchannels. The optimal fluid dynamics geometry was the one where the first block causes the least obstruction to the flow, $\left(H_{11} / L_{11}\right)_{\mathrm{o}, \mathrm{F}}=0.1$ and $\left(L_{12} / L_{11}\right)_{\mathrm{oo}, \mathrm{F}}=0.1$, the same for both values of $\operatorname{Re}_{H}$ and for both with and without boiling.

The multi-objective analysis proved that the geometry of the first block had a considerable higher effect over the pressure drop than over the heat transfer rate and also that the cases with boiling had a better multiobjective performance than those without boiling, for the fluid dynamics and thermal conditions studied here. The optimal geometries found for both $\mathrm{Re}_{H}$ and for the cases with and without boiling were exactly the same, $\left(H_{11} / L_{11}\right)_{\mathrm{o}}=0.1$ and $\left(L_{12} / L_{11}\right)_{\mathrm{oo}}=0.1$, which is the same geometry as the optimal fluid dynamics geometric. Moreover, it is noticeable that the advantage in performance that the cases with the boiling process have for $\operatorname{Re}_{H}=0.1$ slightly decreases for $\operatorname{Re}_{H}=10.0$, although they still better than the cases without boiling. Another import observation is that for $\operatorname{Re}_{H}=10.0$ there was a slight increase in the share of heat transfer in the multiobjective, which leads to the conclusion that there is a possibility that an increase in the Reynolds number above this value can lead to an augmentation of this trend.

In general, the results demonstrated for lower magnitudes of $\mathrm{Re}_{H}$ that the consideration of boiling had not important influence over the design prediction of microchannel for the present thermal conditions and for the degrees of freedom investigated here. In spite of that, the design investigation proved to be important for improvement on the overall performance of microchannels heat exchangers. For future studies, a complete investigation with the four degrees of freedom and under other flow conditions will be performed. 
Acknowledgement: E.D. dos Santos thanks FAPERGS - Fundação de Amparo à Pesquisa do Estado do Rio Grande do Sul for financial support by the Public Call No 05/2019 - PqG (Grant number: 19/2551-00018479). The authors L.A. Isoldi, L.A.O. Rocha and E.D. dos Santos thank CNPq - Conselho Nacional de Desenvolvimento Cientifico e Tecnológico for research grant (Processes: 306012/2017-0, 307791/2019-0, 306024/2017-9).

\section{References}

Bhati, J., Paruya, S., \& Naik L, J. (2020). Numerical Simulation of Bubble Dynamics in Subcooled Flow Boiling in a Channel. Nuclear Engineering and Design, 371, 110945.

Bejan, A. (2013). Convection Heat Transfer. Hoboken, USA: John Wiley \& Sons, Inc.

Bejan, A. (2020). Freedom and Evolution, Hierarchy in Nature, Society and Science. Cham, Switzerland: Springer.

Bejan, A., \& Lorente, S. (2008). Design with Constructal Theory, Hoboken, New Jersey, USA: John Wiley \& Sons.

Bejan, A., \& Lorente, S. (2013). Constructal law of design and evolution: Physics, biology, technology, and society. Journal of Applied Physics, 113, No. 151301.

Bejan, A., \& Zane, J. P. (2012). Design in Nature. New York, USA: Doubleday.

Bello-Ochende, T., Meyer, J. P., \& Bejan, A. (2009). Constructal Ducts with wrinkled entrances. International Journal of Heat and Mass Transfer, 52, 3628-3633.

Biserni, C., Rocha, L. A. O., Stanescu, G., \& Lorenzini, E. (2007). Constructal H-shaped cavities according to Bejan's theory. International Journal of Heat and Mass Transfer, 50, 2132-2138.

Chen, J. C. (1966). Correlation for Boiling Heat Transfer to Saturated Fluids in Convective Flow. Industrial and Engineering Chemistry Process Design and Development, 5, 322.

Collier, J.G., \& Thome, J.R. (1994). Convective Boiling and Condensation. (3rd ed.) Oxford, United Kingdom: Clarendon Press.

Feijó, B. C., Lorenzini, G., Isoldi, L. A., Rocha, L. A. O., Goulart, J. N. V., \& Dos Santos, E. D. (2018). Constructal design of forced convective flows in channels with two alternated rectangular heated bodies. International Journal of Heat and Mass Transfer, 125, 710-721.

FLUENT, Documentation Manual - FLUENT 14.5 (2013).

Ghani, I. A., Sidik, N. A. C., \& Kamaruzaman, N. (2017). Hydrothermal performance of microchannel heat sink: The effect of channel design. International Journal of Heat and Mass Transfer, 107, 21-44.

Gonzales, G. V., Estrada, E. da S. D., Emmendorfer, L. R., Isoldi, L. A., Xie, G., Rocha, L. A. O., \& Dos Santos, E. D. (2015). A Comparison of Simulated Annealing Schedules for Constructal Design of Complex Cavities Intruded into Conductive Walls with Internal Heat Generation. Energy, 93, 372 - 382.

Gonzales, G. V., Lorenzini, G., Isoldi, L. A., Rocha, L. A. O., Dos Santos, E. D., \& Silva Neto, A.J. (2021). Constructal Design and Simulated Annealing Applied to the Geometric Optimization of an Isothermal Double T-Shaped Cavity. International Journal of Heat and Mass Transfer, 174, 121268.

Hermani, L., Lorenzini, G., Klein, R. J., Zinani, F. F., Dos Santos, E. D., Isoldi, L. A., \& Rocha, L. A. O. (2018) Constructal Design Applied to Elliptic Tubes in Convective Heat Transfer Cross-Flow of Viscoplastic Fluids. International Journal of Heat and Mass Transfer, 116, 1054 - 1063.

Kandlikar, S. G., \& Grande, W. J. (2003). Evolution of Microchannel Flow Passages - Thermohydraulic Performance and Fabrication Technology. Heat Transfer Engineering, 25, 1.

Kandlikar, S. G., Shoji, M., \& Dhir, V. K. (1999). Handbook of Phase Change: Boiling and Condensation. Philadelphia, USA: Taylor \& Francis.

Karayiannis, T. G., \& Mahmoud, M. M. (2017). Flow boiling in microchannels: Fundamentals and applications. Applied Thermal Engineering, 115, 25, 1372-1397. 
Khan, M. G., \& Fartay, A. (2011). A review on microchannel heat exchangers and potential applications. Int. J. Energy Res., 35, 553-582.

Lee, W.H. (1980). A Pressure Iteration Scheme for Two-Phase Flow Modeling. Multiphase Transport Fundamentals, Reactor Safety, Applications. Washington, DC, USA.

Lorenzini, G., Garcia, F. L., Dos Santos, E. D., Biserni, C., \& Rocha, L. A. O. (2012). Constructal Design Applied to the optimization of complex geometries: T-Y-shaped cavities with two additional lateral intrusions cooled by convection. International Journal of Heat and Mass Transfer, 55, 1505-1512.

Magalhães, G.C., Fragassa, C., Lemos, R.L., Isoldi, L.A., Amico, S.C., Rocha, L.A.O., Souza, J.A., \& Dos Santos, E.D. (2020). Numerical Analysis of the Influence of Empty Channels Design on Performance of Resin Flow in a Porous Plate. Applied Sciences, 10, 4054.

Manninen, M., Taivassalo, V., \& Kallio, S. (1996). On the Mixture Model for Multiphase Flow. VTT Publications.

Moreira, R.S.M., Escobar, C.C., Isoldi, L.A., Davesac, R.R., Rocha, L.A.O., \& Dos Santos, E.D. (2021). Numerical Study and Geometric Investigation of Corrugated Channels Subjected to Forced Convective Flows. Journal of Applied and Computational Mechanics, 7, 727-738.

Naghibzadeh, S.M., Goharkhah, M., Sharifpur, M., \& Meyer, J.P. (2020). Effects of Interphase Momentum Exchange Models on Simulation of Subcooled Flow Boiling. International Communications in Heat and Mass Transfer, 118, 104863.

Naqiuddin, N.H., Saw, L.H., Yew, M.C., Yusof, F., Ng, T.C., \& Yew, M.K. (2018). Overview of MicroChannel Design for High Heat Flux Application. Renewable and Sustainable Energy Reviews, 82, 901-914.

Nunes, B.R., Rodrigues, M.K., Rocha, L.A.O.; Labat, M., Lorente, S., Dos Santos, E.D., Isoldi, L.A., \& Biserni, C. (2021). Numerical-Analytical Study of Earth-Air Heat Exchangers with Complex Geometries Guided by Constructal Design. International Journal of Energy Research, 45, 20970-20987.

Ohadi, M., Choo, K., Dessiatoun, S., \& Cetegen, E. (2012). Emerging Applications of Microchannels. Briefs in Applied Sciences and Technology, 67-105.

Rai, S.K., Sharma, R., Saifi, M., Tyagi, R., Singh, D., \& Gupta, H. (2018). Review of recent applications of micro channel in mems devices. International Journal of Applied Engineering Research, 13, 9, 64-69.

Rocha, L. A. O., Lorente, S., \& Bejan, A. (2002). Constructal design for cooling a disc-shaped area by conduction. International Journal of Heat and Mass Transfer, 45, 8, 1643-1652.

Rocha, L. A. O., Lorenzini, E., \& Biserni, C. (2005). Geometric optimization of shapes on basis of Bejan's Constructal Theory. International Journal of Heat and Mass Transfer, 32, 1281-1288.

Rodrigues, M. K., Brum, R. B., Vaz, J., Rocha, L. A. O., Dos Santos, E.D., \& Isoldi, L.A. (2015). Numerical investigation about the improvement of the thermal potential of an Earth-Air Heat Exchanger (EAHE) employing the Constructal Design method. Renewable Energy, 80, 538-551.

Rodrigues, P.M., Biserni, C., Escobar, C.C., Rocha, L.A.O., Isoldi, L.A., \& Dos Santos, E.D. (2020). Geometric Optimization of a Lid-Driven Cavity with Two Rectangular Intrusions under Mixed Convection Heat Transfer: A Numerical Investigation Motivated by Constructal Design. International Communications in Heat and Mass Transfer, 117, 104759.

Rohsenow, W.M., Hartnett, J.P., \& Cho, Y.I. (1998). Handbook of Heat Transfer. (3rd ed).USA: McGrawHill.

Schiller, L., \& Nauman, A. (1935). A drag coefficient correlation. VDI Zeitung, 77, 318-320.

Setoodeh, H., Ding, W., Lucas, D., \& Hampel, U. (2020). Modelling and Simulation of Flow Boiling with an Eulerian-Eulerian Approach and Integrated Models for Bubble Dynamics and Temperature-Dependent Heat Partioning. International Journal of Thermal Sciences, 161, 106709.

Siddiqui, O.K., \& Zubair, S.M. (2017). Efficient energy utilization through proper design of microchannel heat exchanger manifolds: A comprehensive review. Renewable and Sustainable Energy Reviews, 74, 969-1002. 
Song, Y., Asadi, M., Xie, G., \& Rocha, L.A.O. (2015). Constructal wavy-fin channels of a compact heat exchanger with heat transfer rate maximization and pressure losses minimization. Applied Thermal Engineering, 75, 24-32.

Vivekanand, S. V. B., \& Raju, V. R. K. (2015). Simulation of Evaporation Heat Transfer in Rectangular Microchannel. Procedia Engineering, 127, 309-316. 